
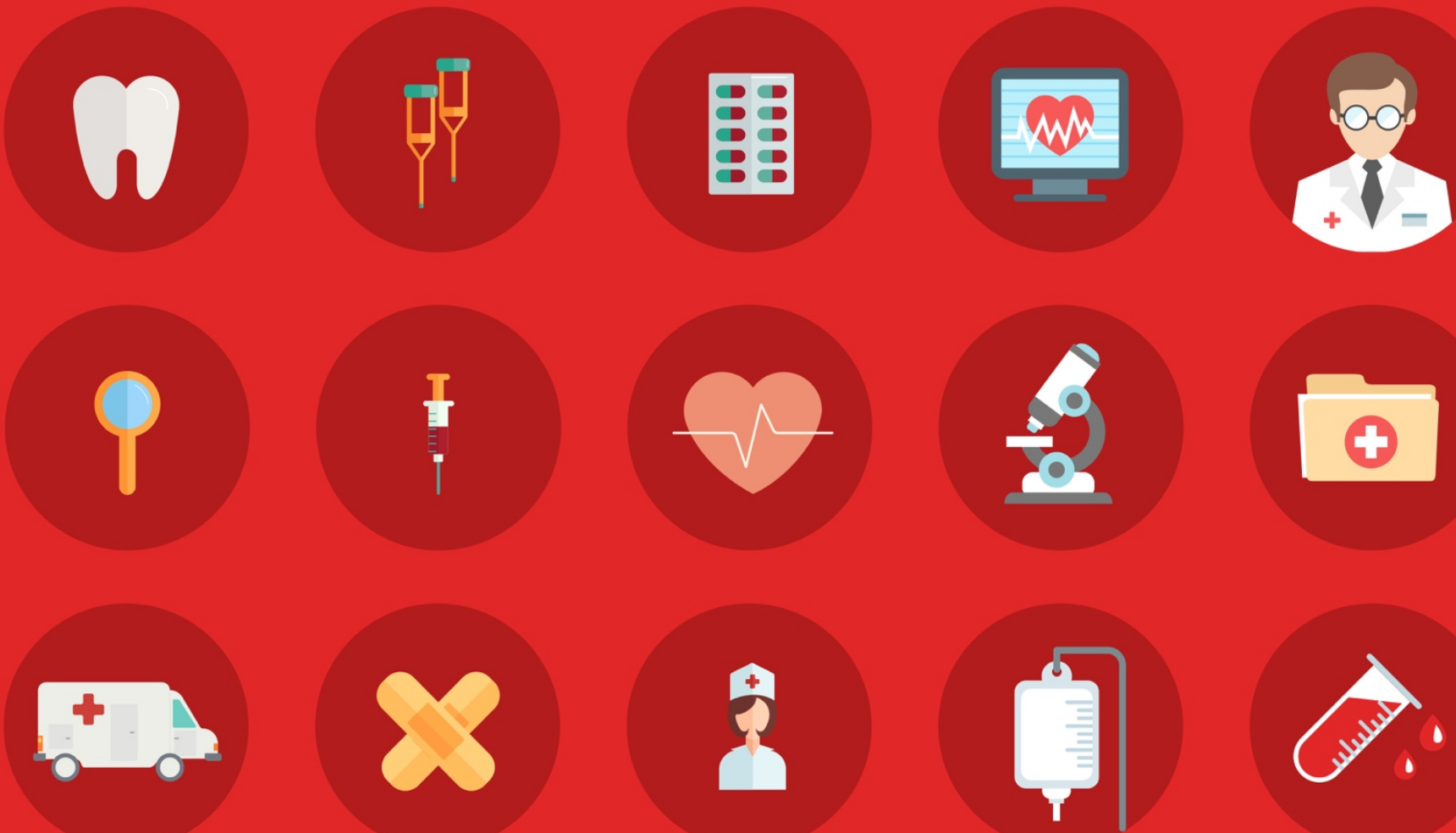

Commentary

\title{
Poor Primary Care Access in Quebec: Barriers and Solutions to Access During an Acute Episode
}

Claire Godard-Sebillotte MD, MSc ${ }^{1}$, Mélanie Le Berre, MSc $\mathrm{PT}^{1}$, Nadia Sourial, MSc ${ }^{1}$, Isabelle Vedel, MD PhD ${ }^{1}$ MJM 2017 15(4)

Access to care is an essential characteristic of an efficient primary care system. One crucial feature of access, which ensures continuity of care and avoids unnecessary emergency department visits, is access to a family doctor during regular hours for an acute health problem (1). According to the Commonwealth Fund's 2015 report on the characteristics of fifteen healthcare systems in developed countries, Quebec has the worst results in terms of access to healthcare services during regular hours (2). Only 39 percent of respondents indicated that they could see a doctor or nurse in a clinic the same day or the next day in Quebec, which stands in contrast to the 47 and 63 percent respectively reported in Ontario and the United Kingdom (2). This commentary focuses on the issues around access to a family doctor during regular hours for an acute health problem. We argue that the proportion of planned primary care consultations is unnecessarily high in Quebec and creates a barrier to consultation with a family doctor for acute episodes. We also argue that the current appointment scheduling scheme in primary care dramatically favours planned consultations over emergency consultations and precludes timely access to primary care. Finally, we outline possible solutions.

\section{Planned annual exams contribute to overcrowding of primary care clinics}

One likely cause of Quebec's poor primary care access is the practice of annual exams among the healthy population. This practice is widespread in

\footnotetext{
${ }^{1}$ Department of Family Medicine, McGill University, Montréal, Canada.

Corresponding Author: Claire Godard-Sebillotte, email Claire.godard-sebillotte@mail.mcgill.ca.
} 
North America; in 2009, annual exams were the second leading cause of medical consultation in Canada and in the United States (3). The large proportion of visits dedicated to the annual exam creates a barrier to consultation with a family doctor for acute episodes. The purpose of this type of visit is to assess the patient's overall health and includes screening tests dictated by age and individual risk factors, such as tobacco use or physical inactivity. (4). However, this practice has been questioned for several years and a systematic review of the literature by the Cochrane Collaboration has shown that annual exams in healthy individuals do not reduce cardiovascular, cancerrelated, or all-cause morbidity and mortality (3). Instead, the review concluded that annual exams favor over-diagnosis through incidental findings (3).

For these reasons, in February 2015, the Collège des médecins du Québec abolished its recommendations for an annual exam. Instead, they recommend that screening or assessment of risk factors be integrated into the overall care of patients during consultations devoted to other problems (4). This could be done using the "Clinical Prevention Sheet", which lists the main risk factors and guidelines for screening/diagnosis (4). Many doctors and patients, however, see annual exams as an essential component of primary care, and moving away from this practice will be slow and complex (4).

\section{Advanced Access: the panacea for Quebec primary care?}

Other causes for the poor access to Quebec's primary care system are the high proportion of followup consultations and the absence of dedicated slots for emergency care. These two concomitant barriers explain in part the difficulties in obtaining a medical appointment during an acute episode (4). We believe more widespread use of Advanced Access provides a solution.

Advanced Access is an appointment management model based on principles from industrial engineering and queueing theory, and was proposed by Dr. Mark Murray, an American family physician (5). It has been effectively implemented to reduce appointment waittimes in primary care in the United States (5). Instead of organizing the doctor's schedule through planned follow-up consultations, the Advanced Access approach focuses on meeting same-day demands (5). During consultations for acute episodes, chronic pathologies and prevention are also addressed. Unlike walk-in clinics, continuity is ensured because this consultation takes place with the patient's own family doctor (5). By applying this method of scheduling appointments, wait times can be substantially reduced, allowing patients with acute episodes to be seen by their physician, as demonstrated in the United States and more locally, in the province of Alberta (6). In Quebec, several trials using Advanced Access have also been successful $(6,7)$. The introduction of Advanced Access was highlighted as a way to promote access in Quebec primary care by the Collège des enseignants de médecine de famille and the Fédération des médecins omnipraticiens du Québec (FMOQ) during negotiations with the Ministry of Health and Social Services (MSSS) over Bill 20 (8).

\section{Advanced Access: conditions and undesired effects}

Two conditions are required for the Advanced Access scheduling method to function successfully: 1) the demand must not exceed the supply; and 2) physicians must offer at least six half days of consultation per week $(5,7)$. If these conditions are not met, the physician will likely be unable to keep up with their patients' needs and a waiting list will again be needed $(5,7)$. In Quebec, although the number of family physicians can theoretically meet the demand, half of their working time is spent on clinical activities other than primary care, due to their obligations with respect to Specific Medical Activities ("Activités Médicales Particulières"; AMPs) (9). In 1998, the MSSS put in place the AMPs system, which requires family physicians with fewer than fifteen years of practice to devote twelve hours per week to one of the six identified priority areas: emergency departments, acute and obstetric hospital services, long-term care and residential centers, rehabilitation centers and home-based care programs for Local Community Service Centers ("Centres Locaux de Services Communautaires"; CLSCs) (9). Lack of compliance with these obligations is penalized through a reduction in remuneration of up to thirty percent for all activities carried out in a private office (9). Maintaining these AMPs presents a barrier for the successful implementation of the Advanced Access scheduling system. To address this barrier, an agreement was signed on May $25^{\text {th }}, 2015$ between the MSSS and the FMOQ modifying the AMPs to also include primary care work (i.e. registration and follow-up of patients) (10). While promising, the implementation of Advanced Access in Quebec will require ongoing efforts by doctors, who will first need to address the already existing waiting lists. It will also present a drastic culture shift for doctors and patients alike, and 
implementing the change is a process that will require time and patience.

Finally, though Advanced Access has many benefits, its use should not be done at the expense of chronic disease management. Follow-up appointments devoted to the management of chronic diseases are paramount for optimal management. Follow-up is integral to the Chronic Care Model proposed by Wagner et al. (11), which is currently recognized as the gold standard of chronic disease management. To prevent this drift, a minimum proportion of follow-up appointments could be considered, adapted to the doctor's practice population. Finding the right balance between follow-up appointments and access to primary care during acute episodes will be the major challenge in Advanced Access implementation in Quebec.

In conclusion, we feel that the negotiations and orientations taken by the Collège des médecins $d u$ Québec and the FMOQ are moving in the right direction by abandoning the recommendation for an annual exam, modifying AMPs to include primary care, and putting forward Advanced Access. Finding the right balance between access, continuity of care, and optimal management of chronic conditions will continue to be a major challenge for those overseeing Quebec's primary care system.

\section{References}

1. Sourial N, Le Berre M, Godard-Sebillotte C, Vedel I. Quebec wins the award for worst emergency wait times in the country: What is main culprit and solution? McGill Journal of Medicine (submitted paper).

2. Comissaire à la santé et au bien-être. Perceptions et expériences de soins des personnes de 55 ans et plus: le Québec comparé Résultats de l'enquète internationnale sur les politiques de santé du Commonwealth Fund de 2014 [Internet]. 2014. Available from: http://www.csbe.gouv.qc.ca/fileadmin/www/2014/CW F/CSBE_Rapport_CWF_2014.pdf

3. Krogsbøll LT, Jørgensen KJ, Grønhøj Larsen C, Gøtzsche PC. General health checks in adults for reducing morbidity and mortality from disease. In: Cochrane Database of Systematic Reviews [Internet]. John Wiley \& Sons, Ltd; 1996 [cited 2015 May 31]. Available from: http://onlinelibrary.wiley.com/doi/10.1002/14651858.C D009009.pub2/abstract

4. Vivement la fin des bilans de santé! [Internet]. L'Actualité. [cited 2015 May 31]. Available from: http://www.lactualite.com/sante-et-science/sante/la- fin-des-bilans-de-sante-et-un-grand-doute-quant-audepistage/

5. Murray M, Berwick DM. Advanced access: reducing waiting and delays in primary care. JAMA. 2003 Feb 26;289(8):1035-40.

6. Premiere ligne. Le pionnier de l'Accès adapté au Québec [Internet]. [cited 2015 May 31]. Available from: http://www.premiereligne.org/?p=1415

7. Groulx A, Casgrain I, Mélançon AP, Huneault L. Adoption of an advanced access model by residents: pilot project at the Gaspé family practice unit. Can Fam Physician Médecin Fam Can. 2015 Jan;61(1):e66-7, 89-91.

8. Fédération des médecins omnipraticiens du Québec. Rapport du groupe de travail sur l'accessibilité aux soins de première ligne [Internet]. Available from: http://www.fmoq.org/Lists/FMOQDocumentLibrary/fr/ Presse/Dossiers/2013-1029_accessibilite/Rapport_acessibilite_.pdf

9. $F M R Q$ - Fédération des médecins résidents du Québec [Internet]. [cited 2015 May 31]. Available from: http://www.fmrq.qc.ca/medecine-familiale/amp

10. Fédération des Médecins Omnipraticiens du Québec. Entente sur des solutions porteuses pour améliorer l'accès aux soins [Internet]. 2015. Available from: http://www.fmoq.org/fr/press/news/news/2015/Lists/ Billets/Post.aspx?ID=7

11. Coleman K, Austin BT, Brach C, Wagner EH. Evidence on the Chronic Care Model in the new millennium. Health Aff Proj Hope. 2009 Feb; 28(1):75-85. 
20 MJM July 2017 Issue 15

mjmmed.com 